\title{
Investigating the Effects of Introducing Automated Straddle Carriers in Port Operations with a System Dynamics Model
}

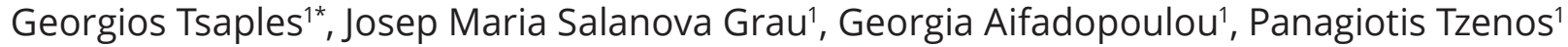 \\ ${ }^{1}$ Hellenic Institute of Transport, Centre for Research and Technology Hellas, 6th km Charilaou-Thermi Rd., 57001 Thermi, \\ Thessaloniki, Greece \\ * Corresponding author, e-mail: gtsaples@uom.edu.gr
}

Received: 04 January 2020, Accepted: 31 January 2020, Published online: 25 November 2021

\begin{abstract}
Port automation has been in the forefront of maritime innovation in the last decade. On that front, Automated Straddle Carriers (ASCs) are increasingly used to move containers efficiently. However, the introduction of ASCs in port operations can be disruptive if not handled properly, especially since the field can face many uncertainties such as increased container trade. The purpose of the paper is to investigate whether the introduction of Automated Straddle Carriers in port operations can improve the overall efficiency. To achieve the objective, a System Dynamics model was developed and tested under different scenarios. The results indicate that the introduction of ASCs is accompanied by an increase in productivity of the vehicles which results in more TEUs serviced. One of the most interesting results of the various scenarios is that for all rates of incoming TEUs, berth productivity is superior when operations are performed with 5 ASCs than with 10 manned vehicles. Finally, another issue that port authorities should always have in mind is the need for coordination among the various sub-processes and optimization of the necessary vehicles in order to avoid under-utilization of resources.
\end{abstract}

\section{Keywords}

system dynamics, port operations, Automated Straddle Carriers (ASCs), autonomous vehicles

\section{Introduction}

The management of a port container terminal is a complex process that involves a large number of decisions at the tactical and strategic level. These decisions rely on human behavior which is prone to mistakes (Hsiao and Richardson, 1999) and it can become even more complicated if it is focused on introducing a new technology that can cause disruptions to the Business-as-Usual scenario.

The situation has become more complex due to an increasing container trade (Carlo et al., 2014) that led port authorities to seek solutions to improve the terminals' efficiency and utilization rate. In that aspect, port automation has been in the forefront of maritime innovation in the last decade. A major part of port automation was focused on the introduction of Automated Straddle Carriers (ASCs).

ASCs are vehicles with stacking capabilities and can move containers horizontally and vertically, thus, they can be used for transporting containers in stacking areas and for loading and unloading road vehicles. Their use provides many advantages: communication and control are easier, human errors are minimized, while their use is considered to be accompanied by an overall improvement in productivity. For that reason, ports around the world have slowly introduced ASCs in their operations. The ones in the Patrick container terminal in Brisbane Australia, and the ECT and Euromax terminals in Rotterdam. can be regarded as successful examples of ASCs.

Regardless of their advantages, introducing ASCs can be a disruptive and costly investment. Furthermore, these vehicles require an established infrastructure and a reliable control system in order to be successfully operated (Carlo et al., 2014). Apart from these physical requirements, there is also the need to gain insights on how smooth the transition period will be for ports, especially when there are combinations of automated and manned vehicles working in parallel that could create deadlocks (Lehmann et al., 2007).

As a result, any decision regarding the introduction and continuous operation of ASCs in ports must be dynamic and under constant evaluation since the circumstances surrounding port terminals are constantly changing. 
Hence, it is often useful to firstly test these decisions in a consequence-free environment before applying them in real-life situations. Due to this multi-dimensional complexity, simulation seems like a natural candidate to help port authorities to address these issues. It allows the representation and analysis of complex and large-scale systems (Quadrat-Ullah and Karakul, 2007), it is easy to use, while providing the opportunity for "what-if" analyses in a consequence-free environment (Zhang and Peeta, 2011) and it can be scaled and adapted to accommodate for different ports and geographical areas.

Terminal operations have been extensively studied in the simulation research. Examples include the modelling of terminals to improve productivity and throughput (Bruzzone and Signorile, 1998) organizational issues and flows of containers (Merkuryev et al., 1998) etc. However, the majority of the studies relies on the paradigm of Discrete Event Simulation that represents operations and movements in a minute-by-minute way (for example (Bodon et al., 2018)) and not many are focused either on the longer-term effects of introducing innovation in port terminals or on how these operations are affected by uncertain external factors.

Hence the objective of the current paper is to investigate whether the introduction of Automated Straddle Carriers in port operations can improve the overall efficiency. To achieve the objective, a System Dynamics model is developed and tested under different scenarios.

The rest of the paper is organized as follows: The next section is focused on the methodology that was followed. It includes a review of the literature on how System Dynamics has been used for maritime modeling and the structure of the simulation model. Results and scenario analysis are presented in the following section, while conclusions and directions of future research are presented in the last section of the paper.

\section{Methodology}

\subsection{Literature review}

As it was mentioned in the introduction, human errors are inherent in any decision-making process regardless if appropriate decision rules are applied (Hsiao and Richardson, 1999). Moreover, due to any port's system complexity, it may be difficult to understand time delays and non-linearities, hence underestimating their effects (Sterman, et al., 2013).

As a result, there is the need to apply methodologies that can help decision-makers to overcome these difficulties and increase the robustness of their decision-making process. Simulation models are considered such a methodology.

They are considered simplistic yet adequate representations of reality (Quadrat-Ullah and Karakul, 2007)that can be used to investigate potential effects of strategies under consideration in an environment that compresses time and space, and were consequences do not translate into actual cost or risk (Armenia et al., 2018).

System Dynamics is a computer-based methodology that can help decision-makers to understand the behaviour of a system over time. They are based on feedback loops and time delays, and they can be used to easily communicate the rationale of a decision (Tsaples and Armenia, 2016).

To investigate how System Dynamics has been used in simulating port operations, a bibliographic search was performed in the relative scientific databases with the keywords "system dynamics" and/or "simulation" and "port operations" along with their derivatives. The initial query revealed that System Dynamics has a limited presence in the port management literature.

Port management has not been extensively studied under the System Dynamics perspective. Dvornik et al. (2006) and Munitić et al. (2003) used System Dynamics to simulate the physical operations of the flow of containers. Sha and Huang (2010) ascended a level and studied the economics and profits of a port system, while Li et al. (2011) looked at ports as pillars in supply chain and analysed the interactions that occur among them. In the paper of Soares and Neto (2016), the authors developed a model to represent and study the dynamics of productivity and capacity in container terminals. The model could be used to gain insights into the development of the container terminal state. Ridwan and Noche (2018) combined System Dynamics with the principles of Six Sigma to measure the performance of ports. Mamatok et al. (2019) studied the $\mathrm{CO}_{2}$ emissions that are generated by port activities, while finally Muravev et al. (2019) combined System Dynamics with Agent-Based modelling to assess the operational capacity and subsequent sustainability of a dry port.

While no claim is made that the above list of papers is exhaustive, some conclusions can be drawn. First, the use of System Dynamics to study port operations is limited. Second, the models that were developed do not explicitly deal with the introduction of automation in ports and finally, the papers do not focus on investigating the effects of changing circumstances in the efficiency in port operations. These are the gaps in the literature that the current paper will address. 


\subsection{Model structure}

The structure of the System Dynamics model represents the flow of containers in the port terminal. Containers are coming in and placed in the berth - respecting the capacity - and must be transported to the storage area, once again taking into account its capacity. Once they are placed in the storage area, they remain there for a random period of time until they are transferred to the trucks' parking area where they are loaded to trucks and being transported outside the port.

The flow is bi-directional; trucks arrive at the port carrying containers that are placed in the storage area (always respecting its capacity) and are transported to the berths to move - this time by ship - outside of the ports.

In the model two types of transportation vehicles are identified: ASCs and manned vehicles. The number of ASCs is an external variable whose value is decided by the decision-maker. One characteristic relation of the model is that the more ASCs are placed for movement by the decision-maker the bigger the delay that is introduced in the average time of movement for each ASC is. This is to be expected since the introduction of a (relatively) large number of ASCs means that the areas of potential collision increase, which in turn means that the variations in speed will be larger, thus making the movement of ASCs slower. Nonetheless, there is a limit to that delay, since after a threshold, the ASCs follow a predefined route constantly that can be thought of as a conveyor belt: the ASCs move - maybe slower than if they were in small numbers - constantly thus increasing again the number of trips that they could perform in a day.
The second type of vehicle in the model is the traditional manned one. The average time that it takes for a trip for this type of vehicles is smaller than that of the ASCs, since the human drivers could cut corners, drive at higher speed etc. However, manned vehicles do not operate as many hours as the automate straddle carriers, since there are shifts and labour intermissions that interrupt the flow of operations. Further delays can be expected during the changing of the shifts, when the drivers need to leave their vehicle and the new ones need to come in. As a result, the individual time of a manned vehicle may be lower than the time for an individual ASC, but the delays that are associated with the human operations may compensate that difference.

Finally, it was assumed that when both types of vehicles are present in the port operations, a new delay would be introduced in the ASCs, since they have to account for the presence of the manned vehicles to avoid collisions, but the opposite does not apply necessarily; humans can avoid collisions by simply pulling down to the side or increasing/reducing the speed above/below the thresholds to avoid the collision. Fig. 1 illustrates the general structure of the System Dynamics model and the causal relations that are formed among the variables.

Finally, to assist with port authorities in using the model as an experimentation and/or decision support tool, a simple User Interface was developed. Fig. 2 illustrates the interface.

The interface consists of the Graphs that illustrate the results, the Decision Variables and the Scenario Variables. The graphs show the results once the simulation ends for the major KPIs of the model. The Decision Variables are

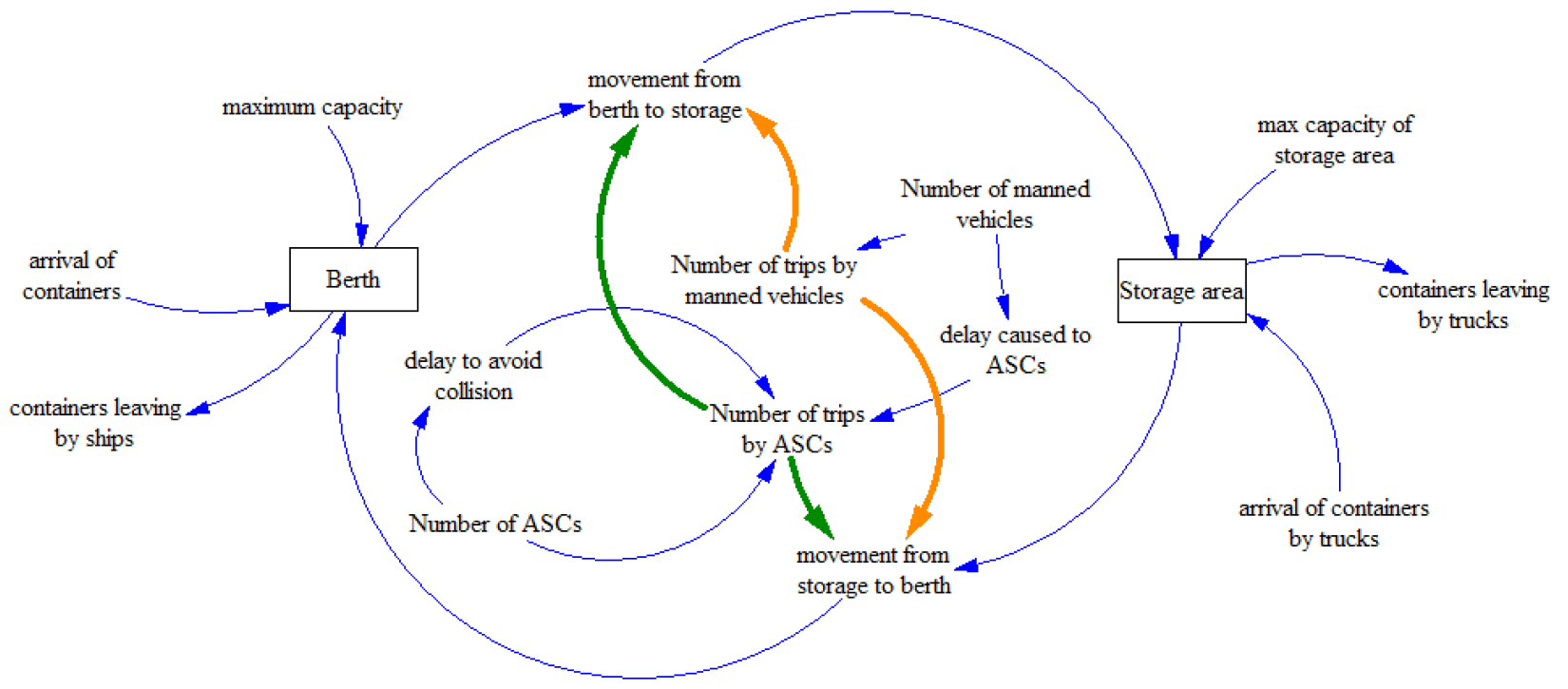

Fig. 1 General structure of the System Dynamics model 


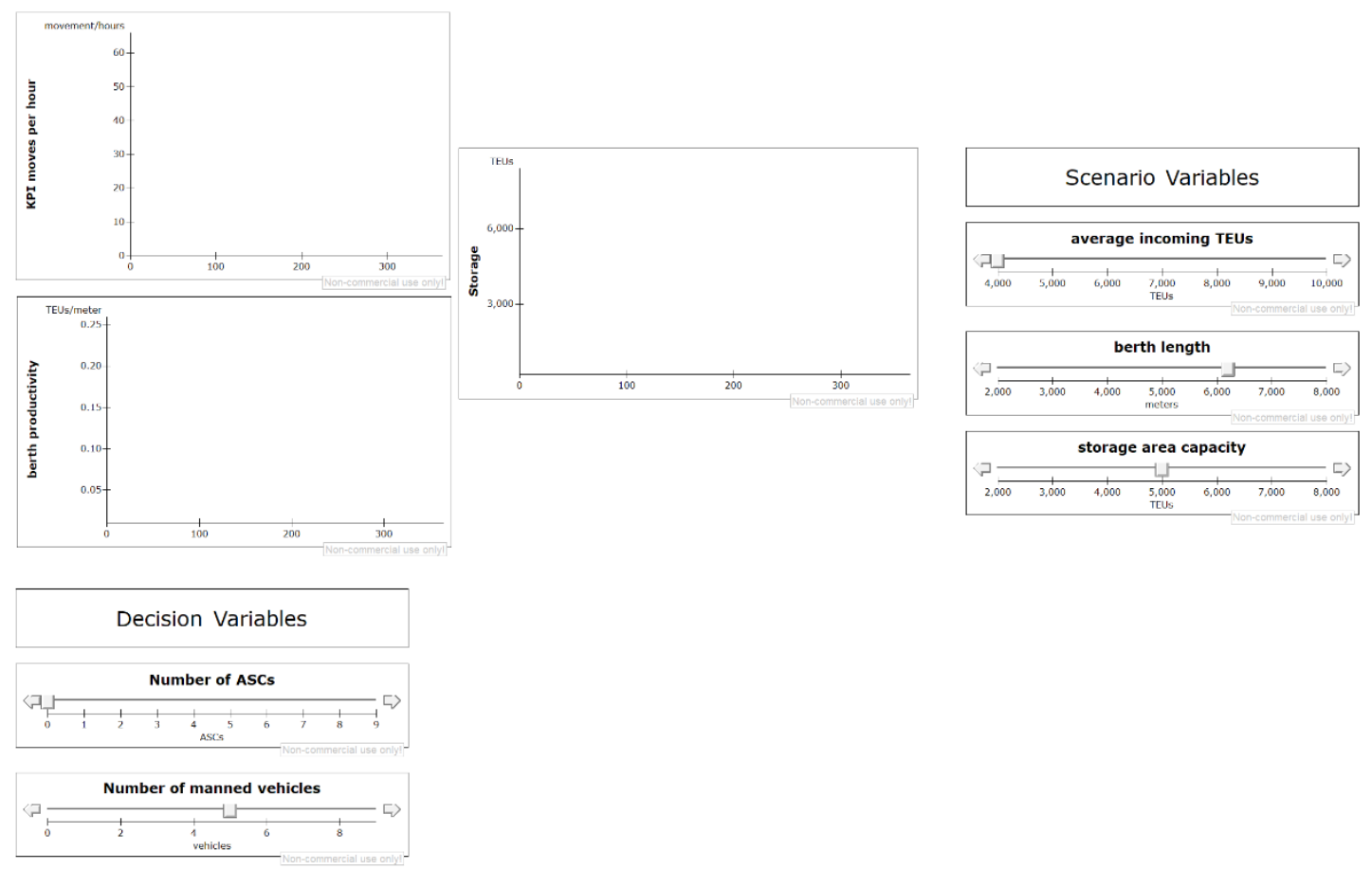

Fig. 2 User Interface of the System Dynamics model

the number of ASCs that are in operation at the simulated port and the number of manned vehicles. Before a simulation run the user can define how many of each type of vehicles will move, or there is also the option to pause the simulation, adjust the decision variable and continue the simulation.

Finally, the Scenarios Variables are the ones that determine the characteristics/attributes of the port (how large it is etc.). To assess the performance of the various decisions, two metrics/Key Performance Indicators were created:

- Movements per hour: It shows how many movements the vehicles perform (manned and ASCs) from crane to storage, from storage to truck parking and the opposite directions covering both full and empty movements.

- Berth productivity: It shows how many TEUs are on the berth and it is measured in TEUs per meter.

\section{Results}

The main scenario variables are the average incoming TEUs per simulated day, the length of the berth area and the capacity of the storage area.

For the basic scenario, the characteristics of the port of Thessaloniki are chosen. The data that were used are taken from the information published by the Port of Thessaloniki on their webpage (Port of Thessaloniki, 2019) and they represent average values:
- Average incoming TEUs $=1000 \mathrm{TEUs} /$ day

- Berth length $=570$ meters

- Storage area capacity $=5000$ TEUs

- $\mathrm{ASCs}=0$

- Manned vehicles $=5$

The base scenario is simulated with the values mentioned above and Fig. 3 illustrates the results.

The results show that the berth productivity is approximately $1.5 \mathrm{TEUs} / \mathrm{meter} /$ Timestep. In storage, as the simulation begins, TEUs are transferred until it reaches its full capacity and approximately at half time of the simulation it stabilizes around 1000 TEUs. Furthermore, the manned vehicles perform in average 17-18 moves per hour (average for the entire period of simulation time and movements carrying a container) with bigger oscillations at the beginning of the simulation.

Furthermore, the model was simulated with 10 manned vehicles under the same operational values (scenario variables). Fig. 4 illustrates the results.

The first result to observe is that the maximum KPI movements per hour reaches higher values, which is to be expected since the number of vehicles was doubled; nonetheless, the average value of the KPI is smaller than in the previous scenario. Regarding berth productivity, it averages around 1.5 TEUs/meter/Timestep, meaning that more TEUs are moved, but the overall average productivity 

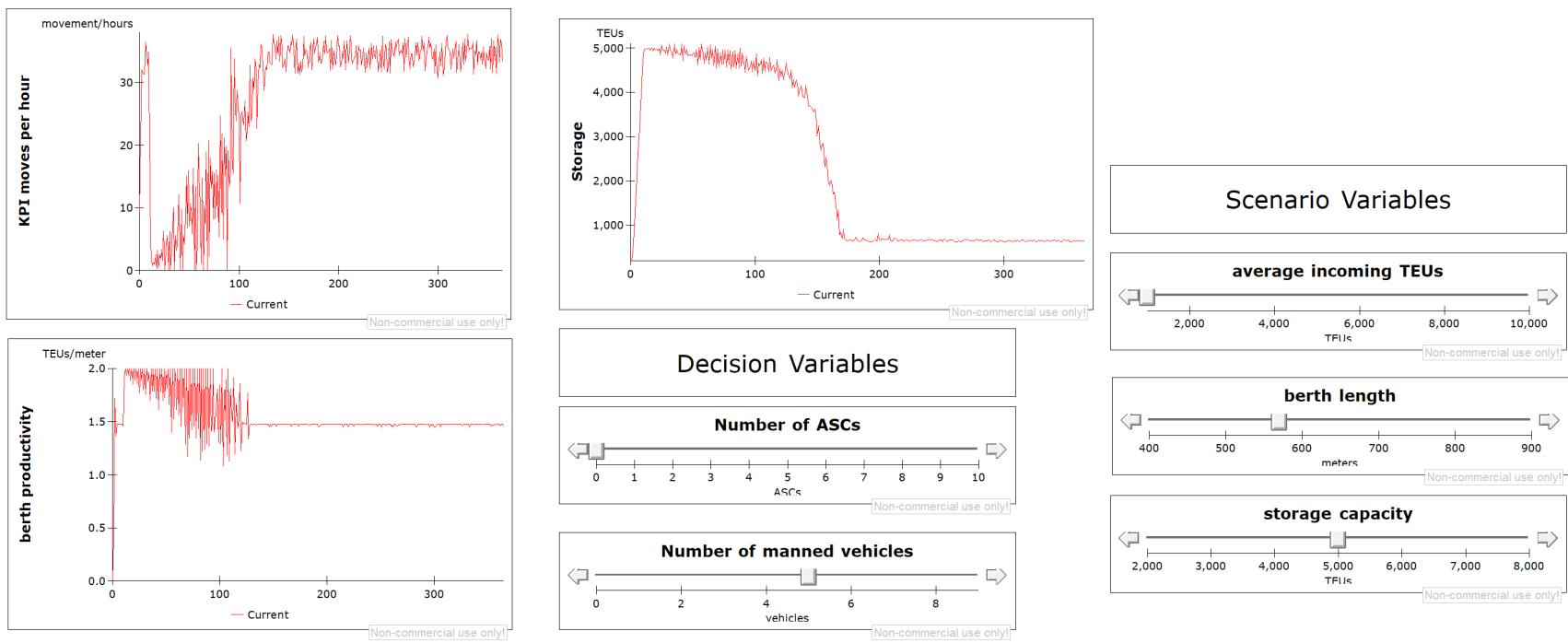

Fig. 3 KPIs graphs and sliders for the base scenario
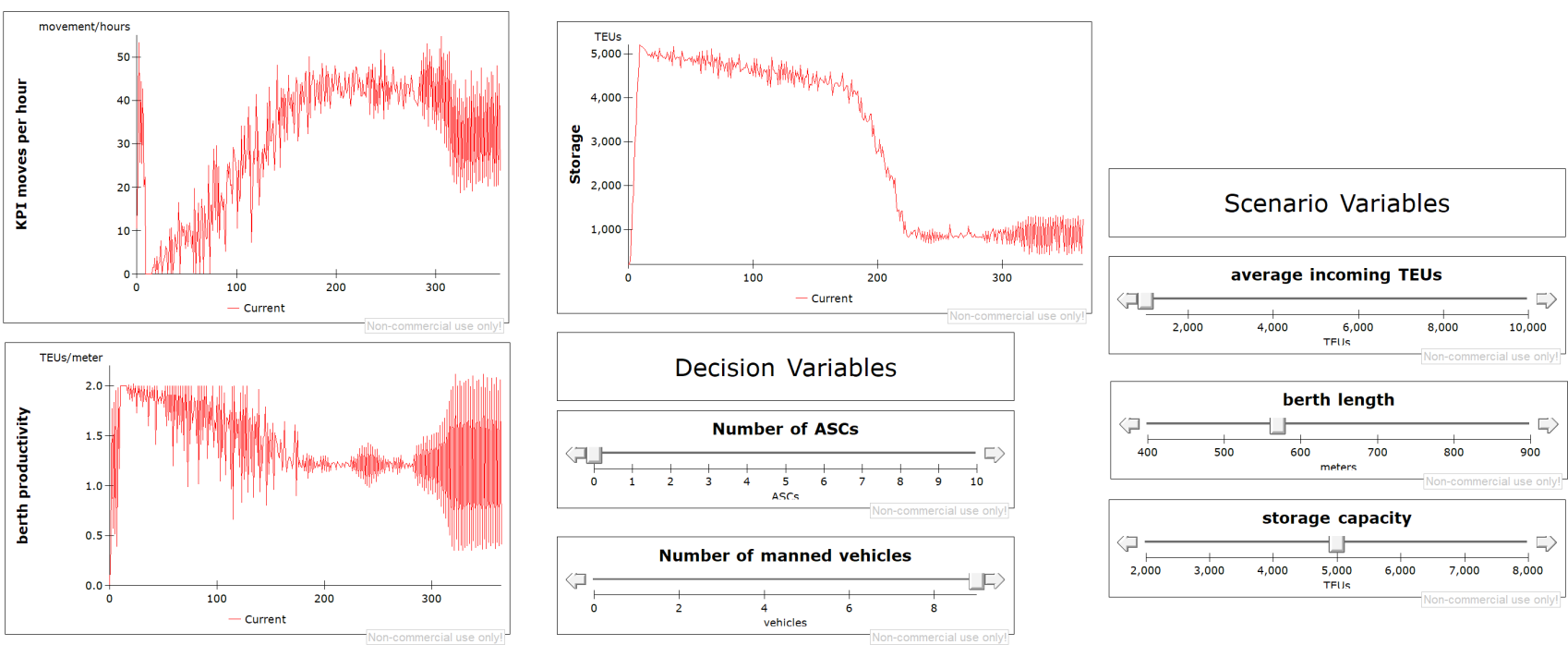

Fig. 4 Simulation with 10 manned vehicles

of the berth remains almost the same. Storage capacity reaches the equilibrium stage at a later point in the simulation time since more containers are moved to storage, thus it takes more movements to transfer them to the truck parking and out of the port.

To compare how the ASCs perform, a new simulation was performed where the manned vehicles were replaced by ASCs. Fig. 5 illustrates the results.

The results illustrate that the average movements per hour for the ASCs is in average 18 movements/hour (carrying a container) while the berth productivity is in average $1.44 \mathrm{TEUs} / \mathrm{meter} / \mathrm{Timestep}$. Interestingly, the results for 5 ASCs are similar to the ones achieved by 10 manned vehicles without the big oscillations that were observed in that scenario.
Finally, a new scenario was simulated by increasing the number of ASCs to 10. Fig. 6 illustrates the results.

The results illustrate that the KPIs perform better than in the previous case, however, oscillations appear at the end of the simulation time. This occurs because the number of 10 ASCs appears to be large for the specific port characteristics: With 10 ASCs moving the berth productivity reaches higher maximum values, meaning that more containers are moved in the storage area. Thus, with fewer containers to be moved, some of the ASCs are not necessary and the average movements per hour decrease. However, the input of containers (TEUs) continues at a steady rate, which increases the needs for movement. Thus, the ASCs that were not necessary start movements again (thus increasing the KPI movements per hour). Hence, since the number of 

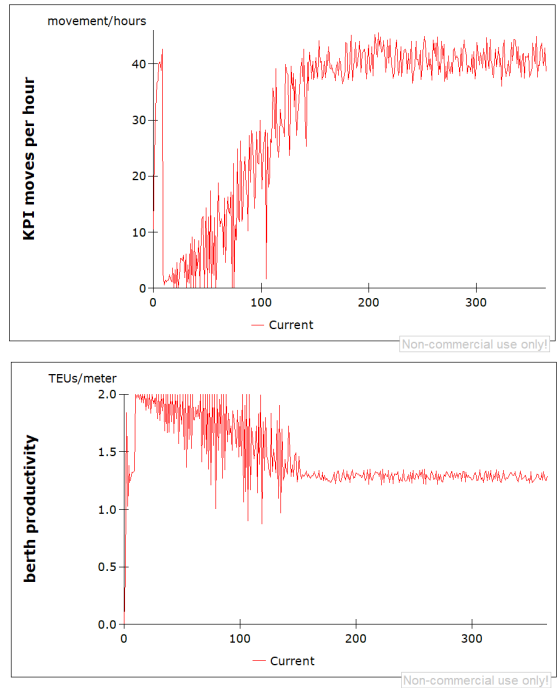
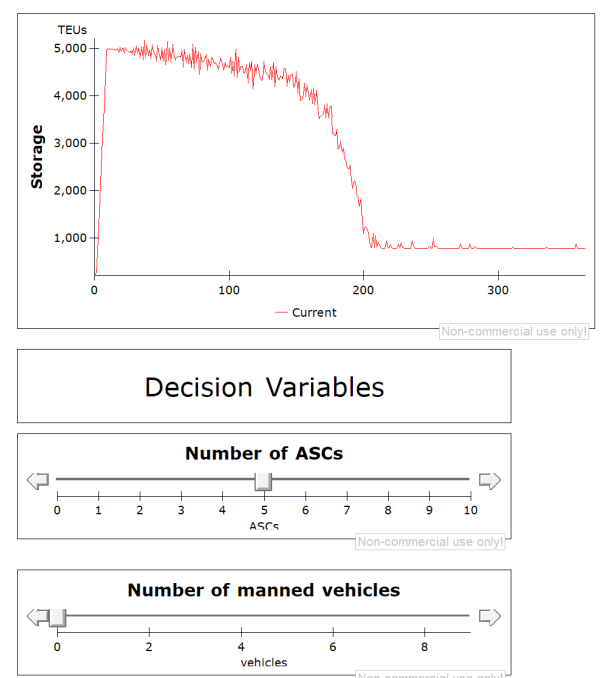
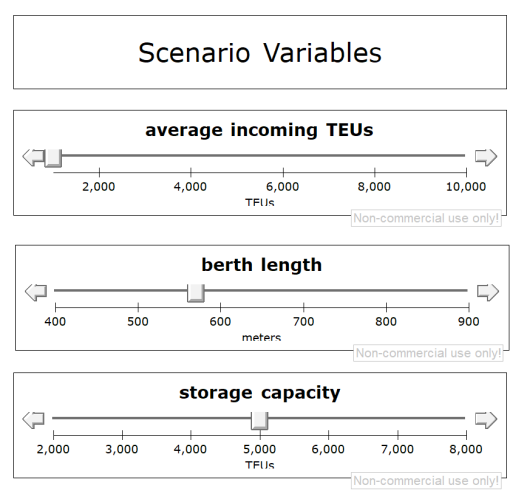

Fig. 5 Results when manned vehicles are replaced by ASCs
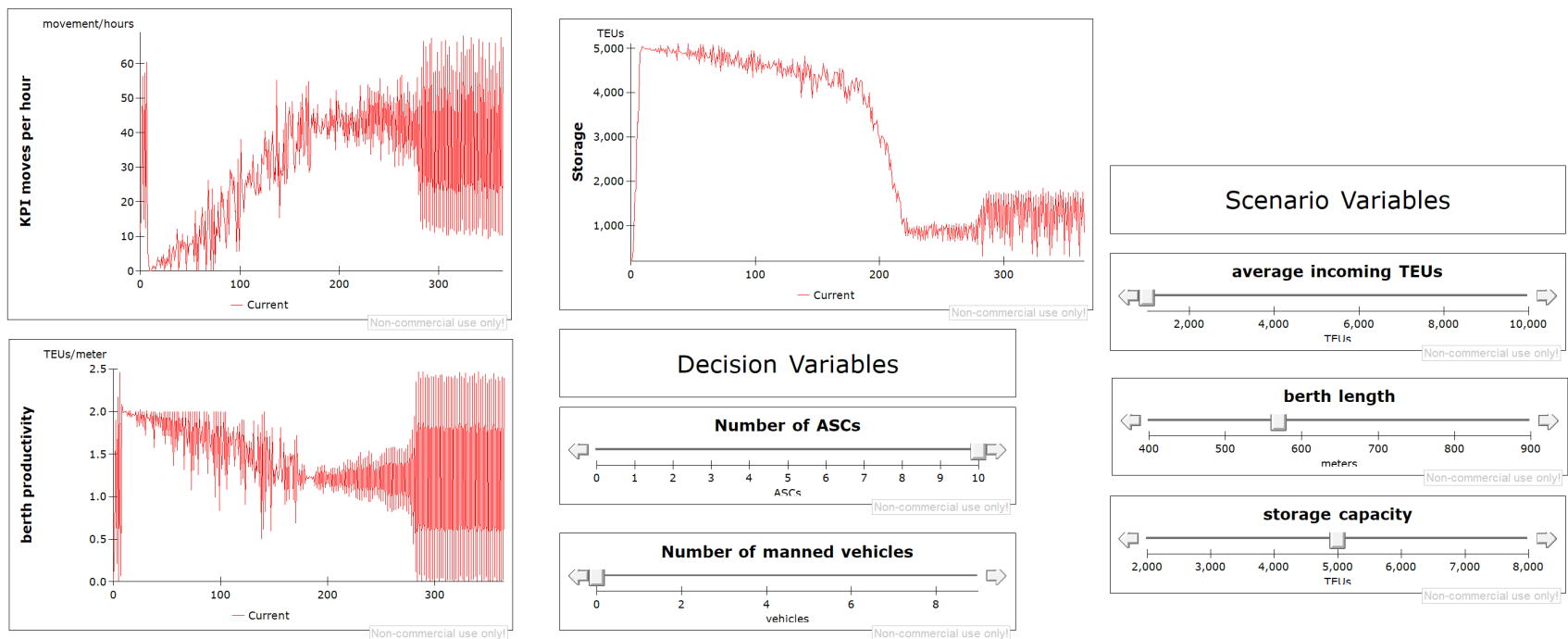

Fig. 6 Results with 10 ASCs

Table 1 Summary result for the performance of the KPIs

\begin{tabular}{|c|c|c|c|c|c|}
\hline KPI & Definition & $\begin{array}{l}\text { Base scenario } \\
\text { (5 manned) }\end{array}$ & $\begin{array}{l}\text { Scenariol } \\
\text { (10 manned) }\end{array}$ & $\begin{array}{l}\text { Scenario } 2 \\
(5 \mathrm{ASCs})\end{array}$ & $\begin{array}{l}\text { Scenario2 } \\
(10 \mathrm{ASCs})\end{array}$ \\
\hline $\begin{array}{l}\text { KPI vehicles } \\
\text { movement per hour }\end{array}$ & $\begin{array}{c}\text { Number of } \\
\text { movements the } \\
\text { vehicles perform }\end{array}$ & 17-18 moves/hour & $\begin{array}{l}13.2 \text { moves per hour } \\
(-25 \%)\end{array}$ & $\begin{array}{l}18 \text { moves per hour } \\
(+9 \%)\end{array}$ & $\begin{array}{c}13.5 \text { moves per hour } \\
(-14 \%)\end{array}$ \\
\hline Berth productivity & $\begin{array}{c}\text { Number of containers } \\
\text { at berth compared to } \\
\text { max capacity }\end{array}$ & 1.5 & 1.5 & 1.44 & 1 \\
\hline
\end{tabular}

ASCs is more than necessary the cycle begins again and for that reason the KPIs generate oscillations.

Thus, at a first glance, introducing ASCs in place of manned vehicles could help the ports to increase productivity since more containers are moved due to the spiking of the productivity of the vehicles.
Table 1 summarizes the performance of the KPIs.

In conclusion, the introduction of ASCs in general acts beneficially to the port processes. However, the introduction of ASCs needs to be adapted to the characteristics of the port in order to avoid having resources that are not necessary for the operations. 


\subsection{Scenario analysis}

The results that were presented above are restricted by the characteristics of the port that was simulated. As a result, to further investigate the effects of automation on port operations, a scenario analysis (in the form of sensitivity analysis) was performed, where the same scenarios were tested for different port characteristics. More specifically, several simulations were made where the values of the Scenario Variables were changed. Table 2 shows the set of values of the scenario variables.

376 combinations were created and simulated. Table 3 shows that regardless of the port characteristics, movements per hour increase when there are ASCs in operation.

In more detail, having 5 Automated Straddle Carriers increases (in average) the movements per hour that are performed, than having 5 manned vehicles. This can be attributed to the fact that ASCs can be in operation 24 hours a day -7 days a week without stop. Furthermore, 10 manned vehicles perform almost similarly as having 5 manned and 5 ASCs. While the best average value is observed when 10 ASCs are in operation.

Table 4 summarizes the average berth productivity for all scenarios. The results indicate that the port operations either with manned vehicles or with ASCs or a combination of the two, share similar results. Interestingly, having a mix of manned vehicles and ASCs produces the lowest

Table 2 Set of values for the scenario variables

\begin{tabular}{|c|c|c|c|c|c|}
\hline Variable Name & Value 1 & Value 2 & Value 3 & Value 4 & Value 5 \\
\hline $\begin{array}{l}\text { Average } \\
\text { incoming TEUs } \\
\text { [TEUs/day] }\end{array}$ & 1000 & 2000 & 4000 & & \\
\hline $\begin{array}{l}\text { Berth Length } \\
\text { [meters] }\end{array}$ & 400 & 570 & 700 & 800 & 900 \\
\hline $\begin{array}{l}\text { Storage area } \\
\text { capacity } \\
\text { [TEUs] }\end{array}$ & 4000 & 5000 & 60000 & 7000 & 8000 \\
\hline $\begin{array}{l}\text { Number of ASCs } \\
\text { [vehicles] }\end{array}$ & 0 & 5 & 10 & & \\
\hline $\begin{array}{l}\text { Number of } \\
\text { manned vehicles } \\
\text { [vehicles] }\end{array}$ & 0 & 5 & 10 & & \\
\hline
\end{tabular}

Table 3 Average movements per hour for ASCs and manned vehicles for all scenarios

\begin{tabular}{lccc}
\hline $\begin{array}{l}\text { Average of Movements per hour } \\
\text { [movements/hour] }\end{array}$ & ASCs & & \\
Manned Vehicles & 0 & 5 & 10 \\
\hline 0 & & 18.7 & 23 \\
5 & 16.2 & 21.8 & \\
10 & 22 & & \\
\hline
\end{tabular}

results for the average berth productivity. This can be attributed to the larger number of potential collisions that need to be avoided between ASCs and manned vehicles.

One of the most interesting results is to contrast the simulated scenarios with 5 ASCs and 10 manned vehicles.

Table 5 indicates that for all rates of incoming TEUs, berth productivity is superior when operations are performed with 5 ASCs than with 10 manned vehicles. Nonetheless, the average movement per hour is lower for the ASCs. Thus, a trade-off must be negotiated when port authorities decide to introduce Automated Straddle Carriers. Depending on their pricing model, 1 ASC can be almost as good as 2 manned vehicles.

The increase in overall productivity of the port can be observed also when contrasted with the other scenario variables.

Table 6 illustrates the maximum values for the KPI berth productivity that were observed for the various sets of runs during which the variable "Berth Length" changed. For the majority of the simulations, the KPI reaches its maximum value with 10 ASCs and no manned vehicles. Interestingly, for "Berth Length" $=570$ meters, which is the length for the base case simulations (Port of Thessaloniki Characteristics) the maximum values are observed for 10 manned vehicles. However, with the current incoming rate of TEUs (100TEUs) 10 ASCs perform better than 10 manned vehicles, and only with an increase in incoming TEUs - without expanding berth length and storage capacity - manned vehicles appear to perform better.

Table 4 Average berth productivity for ASCs and manned vehicles for all scenarios

\begin{tabular}{lccc}
\hline $\begin{array}{l}\text { Average of Berth Productivity } \\
\text { [TEUs/meter] }\end{array}$ & ASCs & & \\
Manned Vehicles & 0 & 5 & 10 \\
\hline 0 & & 1.57 & 1.41 \\
5 & 1.61 & 1.45 & \\
10 & 1.40 & & \\
\hline
\end{tabular}

Table 5 Comparison of scenarios with 5 ASCs and 10 manned vehicles

\begin{tabular}{lcccc}
\hline & $\begin{array}{c}\text { Berth Productivity } \\
\text { [TEUs/meter/timestep] }\end{array}$ & $\begin{array}{c}\text { Average Movement per } \\
\text { Hour [movements/hour] }\end{array}$ \\
$\begin{array}{l}\text { Average rate } \\
\text { of incoming } \\
\text { TEUs } \\
\text { [TEUs/day] }\end{array}$ & 5 ASCs & 10 manned & 5 ASCs & 10 manned \\
\hline 1000 & 1.51484 & 1.3004 & 17.4 & 17.7 \\
2000 & 1.5452 & 1.3908 & 20.5 & 24 \\
4000 & 1.6696 & 1.53432 & 18.1 & 24.2 \\
\hline
\end{tabular}


Table 6 Maximum values for berth productivity for each value of berth length

\begin{tabular}{|c|c|c|c|c|c|c|}
\hline $\begin{array}{l}\text { Rate of incoming } \\
\text { TEUs [TEUs/day] }\end{array}$ & $\begin{array}{l}\text { berth length } \\
\text { [meters] }\end{array}$ & $\begin{array}{c}\text { Storage area } \\
\text { capacity [TEU] }\end{array}$ & $\begin{array}{c}\text { Number of } \\
\text { ASCs }\end{array}$ & $\begin{array}{c}\text { Number of } \\
\text { manned vehicles }\end{array}$ & $\begin{array}{l}\text { Movements per hour } \\
\text { [movements/hour] }\end{array}$ & $\begin{array}{l}\text { Berth Productivity } \\
\text { [TEUs/meter/timestep] }\end{array}$ \\
\hline 1000 & & 8000 & 10 & 0 & 21.5 & 2.3 \\
\hline 2000 & 400 & 7000 & 10 & 0 & 29 & 2.84 \\
\hline 4000 & & 4000 & 0 & 10 & 18.3 & 2.34 \\
\hline 1000 & & 4000 & 10 & 0 & 23.5 & 1.97 \\
\hline 2000 & 570 & 6000 & 0 & 10 & 22 & 2.1 \\
\hline 4000 & & 6000 & 0 & 10 & 20.7 & 2.17 \\
\hline 1000 & & 6000 & 0 & 5 & 16.7 & 1.62 \\
\hline 2000 & 700 & 4000 & 10 & 0 & 30 & 2.15 \\
\hline 4000 & & 8000 & 10 & 0 & 30 & 2.29 \\
\hline 1000 & & 5000 & 5 & 0 & 18.9 & 1.59 \\
\hline 2000 & 800 & 7000 & 10 & 0 & 28 & 1.97 \\
\hline 4000 & & 8000 & 10 & 0 & 30 & 2.16 \\
\hline 1000 & & 5000 & 0 & 5 & 28 & 1.69 \\
\hline 2000 & 900 & 4000 & 10 & 0 & 30 & 1.89 \\
\hline 4000 & & 5000 & 10 & 0 & 31.3 & 2.12 \\
\hline
\end{tabular}

\section{Conclusions}

The objective of the current paper was to investigate whether the introduction of Automated Straddle Carriers in port operations can improve the overall efficiency of the port. To achieve the objective, a System Dynamics model was developed. A search in the literature indicated that System Dynamics has not been extensively used to study aspects of ports and their operations.

As a result, the developed model represents operations and movements within a container port. Subsequently, the model was tested for a large combination of parameters, representing different scenarios.

The results indicate that the introduction of ASCs is accompanied by an increase in productivity of the vehicles which results in more TEUs serviced. This result is especially important for an increased rate of incoming TEUs; the use of Automated Straddle Carriers results in the highest values of the KPIs. One of the most interesting results of the various scenarios is that for all rates of incoming TEUs, berth productivity is superior when operations are

\section{References}

Armenia, S., Tsaples, G., Carlini, C. (2018) "Critical Events and Critical Infrastructures: A System Dynamics Approach", In: Dargam, F., Delias, P., Linden, I., Mareschal, B. (eds.) Decision Support Systems VIII: Sustainable Data-Driven and Evidence-Based Decision Support. ICDSST 2018., Lecture Notes in Business Information Processing, 313, Springer, Cham, Switzerland, pp. $55-65$.

https://doi.org/10.1007/978-3-319-90315-6_5 performed with 5 ASCs than with 10 manned vehicles. Nonetheless, the average movement per hour is lower for the ASCs. Thus, a trade-off must be negotiated when port authorities decide to introduce Automated Straddle Carriers.

Another issue that port authorities should always have in mind is the need for coordination among the various sub-processes and optimization of the necessary vehicles in order to avoid under-utilization of resources.

The model at its current form does not come without limitations. As a result, upgrades are necessary that could increase its value. These could focus on expanding the model to simulate specific decisions related to berth and storage capacity, thus transforming them from scenario to decision variables. The introduction of a spatial dimension could direct the model towards a functionality as a Decision Support System. Finally, the System Dynamics model could be combined with other techniques to develop a more holistic system of port management that could help port authorities make better decisions at both the operational and strategic level.
Bodon, P., Fricke, C., Sandeman, T., Stanford, C. (2018) "Combining Optimisation and Simulation to Model a Supply Chain from Pit to Port", In: Dimitrakopoulos, R. (ed.) Advances in Applied Strategic Mine Planning, Springer, Cham, Switzerland, pp. 251-267. https://doi.org/10.1007/978-3-319-69320-0_17

Bruzzone, A., Signorile, R. (1998) "Simulation and Genetic Algorithms for Ship Planning and Shipyard Layout", Simulation, 71(2), pp. 74-83. https://doi.org/10.1177/003754979807100202 
Carlo, H. J., Vis, I. F. A., Roodbergen, K. J. (2014) "Transport operations in container terminals: Literature overview, trends, research directions and classification scheme", European Journal of Operational Research, 236(1), pp. 1-13. https://doi.org/10.1016/j.ejor.2013.11.023

Dvornik, J., Munitić, A., Bilić, M. (2006) "Simulation Modelling and Heuristics Optimization of Material Flow of the Port Cargo System", Promet-Traffic\&Transportation, 18(2), pp. 123-135.

Forrester, J. W. (1961) "Industrial Dynamics", The M.I.T. Press, Cambridge, MA, USA.

Hsiao, N., Richardson, G. P. (1999) "In Search of Theories of Dynamic Decision Making: A Literature Review", In: 17th International Conference of the System Dynamics Society, Wellington, New Zealand, CDROM. [online] Available at: http://citeseerx.ist. psu.edu/viewdoc/summary?doi=10.1.1.604.7412 [Accessed: 02 December 2019]

Lehmann, M., Grunow, M., Gunther, H-O. (2007) "Deadlock handling for real-time control of AGVs at automated container terminals", In: Kim, K. H., Günther, H-O. (eds.) Container Terminals and Cargo Systems, Springer, Berlin, Heidelberg, Germany, pp. 215-241. https://doi.org/10.1007/978-3-540-49550-5_11

Li, J., Li, W., Lin, Y. (2011) "Port Supply Chain Simulation Model under Interactive Analysis", Procedia Engineering, 15, pp. 2082-2086. https://doi.org/10.1016/j.proeng.2011.08.389

Mamatok, Y., Huang, Y., Jin, C., Cheng, X. (2019) "A System Dynamics Model for CO2 Mitigation Strategies at a Container Seaport", Sustainability, 11(10), Article number: 2806. https://doi.org/10.3390/su11102806

Merkuryev, Y., Tolujew, J., Blümel, E., Novitsky, L., Ginters, E., Viktorova, E., Merkuryeva G., Pronins, J. (1998) "A Modeling and Simulation Methodology for Managing the Riga Harbor Container Terminal", Simulation, 71(2), pp. 84-95. https://doi.org/10.1177/003754979807100203

Munitić, A., Šimundić, S., Dvornik, J. (2003). "System Dynamics Modelling of Material Flow of the Port Cargo System", In: The 21st International Conference of the System Dynamics Society, Albany, NY, USA, pp. 97-114.

Muravev, D., Rakhmangulov, A., Hu, H., Zhou, H. (2019) "The Introduction to System Dynamics Approach to Operational Efficiency and Sustainability of Dry Port's Main Parameters", Sustainability, 11(8), Article number: 2413.

https://doi.org/10.3390/su11082413
Port of Thessaloniki, ThPA S. A. (2019) "ThPA S:A: Port of Thessaloniki" [online] Available at: https://www.thpa.gr/index.php/en/olth/ statistics [Accessed: 02 December 2019]

Quadrat-Ullah, H., Karakul, M. (2007) "Decision Making in Interactive Learning Environments Towards an Integrated Model", Journal of Decision Systems, 16(1), pp. 79-99. https://doi.org/10.3166/jds.16.79-99

Ridwan, A., Noche, B. (2018) "Model of the port performance metrics in ports by integration six sigma and system dynamics", International Journal of Quality \& Reliability Management, 35(1), pp. 82-108. https://doi.org/10.1108/IJQRM-03-2016-0041

Sha, M., Huang, X. (2010) "A system dynamics model for port operation system based on time, quality and profit", In: International Conference on Logistics Systems and Intelligent Management, Harbin, China, pp. 1669-1673. https://doi.org/10.1109/iclsim.2010.5461258

Soares, C. J. M., Neto, H. X. R. (2016) "A Model for Predictable Capacity of a Container Terminal State: A System Dynamics Approach", Journal of Traffic and Transportation Engineering, 4(3), pp. 141-154. https://doi.org/10.17265/2328-2142/2016.03.003

Sterman, J. D. (2000) "Business Dynamics: Thinking and Modeling for a Complex World", McGraw-Hill Education, New York, USA.

Sterman, J. D., Fiddaman, T., Franck, T., Jones, A., McCauley, S., Rice, P., Sawin, E., Siegel, L. (2013) "Management flight simulators to support climate negotiations", Environmental Modelling \& Software, 44, pp. 122-135.

https://doi.org/10.1016/j.envsoft.2012.06.004

Tsaples, G., Armenia, S. (2016) "Studying pension systems and retirement age: a simple system dynamics model for a complex issue", International Journal of Applied Systemic Studies, 6(3), pp. 258-270. https://doi.org/10.1504/IJASS.2016.079095

Zhang, P., Peeta, S. (2011) "A generalized modeling framework to analyze interdependencies among infrastructure systems", Transportation Research Part B: Methodological, 45(3), pp. 553-579. https://doi.org/10.1016/j.trb.2010.10.001 